\title{
Role of Infrastructure to improve quantity and enhance quality of School Education in Sindh Province of Pakistan
}

\author{
Mr. Mazhar Ali Siddique \\ Director General Planning Development \& Research, \\ School Education \& Literacy Department Government of Sindh Karachi, Pakistan.
}

\author{
Mr. Ali Akbar Tagar \\ Section Officer (Development) \\ School Education \& Literacy Department Government of Sindh Karachi, Pakistan.
}

\section{Mr. Zamir Ahmed Khoso}

Regional Director

College Education Department Government of Sindh Karachi, Pakistan.

\author{
Dr. Hamzo Khan Tagar \\ Director Public Private Partnership Node, \\ School Education \& Literacy Department, Government of Sindh, Karachi Pakistan.
}

\begin{abstract}
The study overviews the current status of school's infrastructure and its nexus with improvement in rate of literacy and improvement in quality of education in the Sindh, the southern province of Pakistan where more than forty percent people are illiterate and females are double than that and these low literacy trends are particularly in far flung area of the region i.e. costal, deserted and hilly region of the rural belt with poor infrastructure and lack of communications at large in compressions of Ruben center's literacy rate. The paper examines the key infrastructural problems and discuss significance of possibilities in the infrastructural sub sector to improve the structure as a sustainable solution and its impact on literacy trends and quality particularly on female literacy. The study finds that development allocation and utilization trends are increasing but there is no improvement in infrastructure as per utilization's trends due to mismanagement at large and improper and unsustainable planning on the subject. The major obstacle in the system is the un availability of procurement directorate for well-planned and timely procurement to save the precious available funding with their proper monitoring and best rationalized utilization in decent transparent manners. It is also concluded that significant increase in literacy rate and quality enhancement is strongly correlated with infrastructural improvement at large and should be focused by the policy makers and international donners organizations in the greater interest of human development in the region.
\end{abstract}

Keywords: Coherent Development Planning, Literacy, Policy, Quality Education, Sustainable Development Goals (SDGs).

\section{INTRODUCTION}

Education and Literacy has great significance and positive effects on the civil society and creates equity among people. It is more beneficial for backward tribes /communities and societies and for sustainable development of the nations under grip of absolute poverty and breaks vicious circle of poverty, creates best approach for health and health and hygiene issues, to create political awareness for the fundamental rights in feudal and undemocratic societies and better to use natural resources in decent manners. "Education lays the foundation of a developed and progressive society. It empowers and creates ability among the individuals 
and the societies to utilize their human capabilities and builds a strong correlation with socioeconomic development. In this regard, the development of a widely accessible quality and equitable education system is a critical requirement" [1].

Sindh is the southern, second largest and most populace province, rich with others natural resources and it has first position in some important economic indicators due to seaports, industries and rich oil and gas energy reservoirs. It is the province of more than 50 million people and projected to be 90 million by 2030. It's dilemma of the region with having rich natural and economic resources Sindh is in grip of poverty, literacy, unemployment, law and order rural urban divides and others socio economic indicators. It is also important to mentioned that in education and literacy its lagging behind in comparison of others provinces because of several obstacles in improving public sector schools' educations one of the important obstacles is poor infrastructure services provided by the government and because of it out of school children low female literacy trends and demand for private schools are on the rise The above-mentioned socioeconomic backwardness is by designed or by natural it is question for further research on the issues. prominent scholar of the country believes that in our country the southern and northern divided is created by design. The Sindh and Baluchistan the southern province of Pakistan is rich with all kinds of resources but very poor and deteriorated in socio economic indicators' in comparisons of northern regions which have tinny resources. "Education sector in Sindh is facing a number of challenges in the form of low levels of school enrollments, high dropout rates specially at the primary and the secondary levels and particularly for the girls in the rural areas, poor quality of teaching and learning, teacher absenteeism, shortage of trend and qualified teachers-especially females, poor management and supervision structure, gender and rural urban imbalances, inappropriateness of curricula and pedagogy, lack of vision in community participation process and financial regularities"[2].

The Alif Ailaan (Reputed Local NGO) Report (2017) reveals that "Sindh's school infrastructure score is $54 \%$. Only $48 \%$ of the primary schools have electricity facility, $58 \%$ schools have drinking water, $64 \%$ have toilets, $65 \%$, have the boundary wall, and importantly only $35 \%$ school's buildings have been found in satisfactory condition. KPK provincial government school infrastructure scores $90 \%$. Eighty-seven percent primary schools have electricity, water is ensured in $89 \%$ schools, $95 \%$ schools have toilet facility, 95\% schools have boundary walls, $87 \%$ of the school buildings are in satisfactory condition. In the province of Punjab, school infrastructure score is $89 \%$. Eighty-nine percent of the primary schools have electricity, $98 \%$ have drinking water availability, 97\% have toilet facility, 93\% school buildings have boundary walls, and 68\% schools' buildings are in good condition". [3]

When we overviewed the problems of Education Department, government of Sindh we may conclude that there are multiple challenges in the system as out of school children and illiterate adults, financial constraints and resources requirement, weak coordination between different tiers of governments, limited institutional capacity to design, plan, manage and implement programs and projects but infrastructural issues are very important in literacy nexus particularly in case of female literacy in the province as 36\% in the urban center and only $19 \%$ in rural and far-flung areas which need concrete infrastructural and sustainable policy towards global goals agenda implantation in the region. This paper has been written to evaluate the above referred component in details and to provide policy recommendation for further necessary improvement in larger public inters which is sustainable future of the tomorrow people in Sindh region and correlated with school's infrastructural development for quality education for all in the province. The study proposes strategies that can be used by the policy makers and implementers to improve the ratio of enrollment and quality of educations. 
Accordingly, the findings of the study can be used by the key players in this country to strengthen their respective roles, thereby improving the tapping and delivering of the potential of the human resources. Such key players include: The Ministries of education at provincial and federal level, political, authorities, global actor/donors' partners and people of the country.

\section{Objectives of the Study}

The specific objectives of the study were to:

i. A strategic review of Sindh performance in school education and literacy in context of schooling infrastructure.

ii. Assess the major obstacles in infrastructural development of the province and its nexus with literacy.

iii. Formulate sustainable development plan to increase quantity and quality of education in the region.

\section{Research Questions}

The study was guided by the following questions:

I. what is the present status of Sindh province 's educations in context of literacy and infrastructure?

II. How have Sindh planned schools infrastructural improvements?

III. can we formulate sustainable development strategy to bring improvement in schools' infrastructure in midterm plan?

\section{Significance of the Study}

The study examines Sindh southern province schools' infrastructural problems and proposes coherent mid-term plan that can be used by the policy makers and implementers to improve the ratio of enrollment and quality of educations.

\section{METHODOLOGY\& DATA}

Exploratory research method is adopted in the paper which is a type of research conducted because a problem has not been clearly defined. Exploratory research often relies on secondary research such as reviewing available literature or qualitative approaches such as informal discussions and more formal approaches through in-depth projective methods, case studies or pilot studies. The results of exploratory research can provide significant insight into a given situation. Evidences from Economic Survey of Pakistan, Secondary data of Federal Bureau of Statistics Sindh Bureau of statistic, Sindh Education management information system (SEMIS) National Education Management Information System (NEMIS) Alif Ailaan annual publication are used.

\section{DISCUSSIONS AND RESULT}

The state of basic facilities in the schools and issue of quality and out of school's children The state of education facilities may be one of the major reasons for a lower enrolment with high dropout rate at the school level in Sindh province, because no one is ready to enroll their child in dangers buildings and girls in without toilet schools. This phenomenon is reviled in entire world to save and safe their child first then to literate/skilled to be a good human resource. The earlier studies conducted on subject concludes that infrastructures are strongly nexuses with increase in quality or literacy rate and also plays significant role to enhance the quality of education at large. In first instance table 01 shows the current statues of school building in Sindh out of 42383 building of schools 95948 buildings are under public sector ownerships, 160 are rented building from private sector. The table 01 also shows district wise status of infrastructures of the province in details. 
Table01.

\begin{tabular}{|c|c|c|c|c|c|c|}
\hline & \multicolumn{6}{|c|}{ Schools Building by Ownership } \\
\hline District Name & OWN Govk Building & \begin{tabular}{|c|} 
Other Govi School \\
Building ( SHARED )
\end{tabular} & RENTED & OTHER Building & $\begin{array}{l}\text { No Building / } \\
\text { Shelterless }\end{array}$ & Total \\
\hline Badin & 2,277 & 28 & 3 & 37 & 589 & 2,934 \\
\hline Dadu & 1,598 & 23 & 4 & 33 & 163 & 1,821 \\
\hline Hyderabad & 829 & 11 & 4 & 8 & 16 & 868 \\
\hline Thatta & 1,119 & 12 & & 88 & 63 & 1,282 \\
\hline \begin{tabular}{|l|} 
Jamshoro \\
\end{tabular} & 653 & 7 & & 12 & 22 & 694 \\
\hline Mitiari & 728 & 12 & 2 & 30 & 57 & 829 \\
\hline Tando Allah Yar & 675 & 17 & 5 & 33 & 30 & 760 \\
\hline Tando Muhammad Khan & 868 & 14 & 1 & 36 & 93 & 1,012 \\
\hline Sujawal & 1,203 & 8 & 4 & 33 & 142 & 1,390 \\
\hline Central Karachi & 541 & 3 & 24 & 29 & 9 & 606 \\
\hline EastKarachi & 239 & & 20 & 14 & 5 & 278 \\
\hline South Karachi & 299 & 5 & 6 & 19 & 1 & 330 \\
\hline West Karachi & 522 & 13 & 5 & 21 & 8 & 569 \\
\hline Malir Karachi & 600 & 12 & 10 & 11 & 30 & 663 \\
\hline Korangi Karachi & 368 & 12 & 1 & 12 & 18 & 411 \\
\hline Jacobabad & 1,062 & 6 & 11 & 36 & 312 & 1,427 \\
\hline Larkana & 1,039 & 21 & 6 & 8 & 84 & 1,158 \\
\hline Shikarpur & 980 & 23 & 2 & 26 & 70 & 1,101 \\
\hline Kashmore & 828 & 7 & 2 & 29 & 502 & 1,368 \\
\hline Kambar-Shahdadkot & 1,269 & 44 & 1 & 50 & 134 & 1,498 \\
\hline Khairpur Mirs & 2,994 & 14 & 6 & 35 & 241 & 3,290 \\
\hline Sukkur & 996 & 21 & 3 & 48 & 119 & 1,187 \\
\hline Ghotki & 1,450 & 20 & & 28 & 393 & 1,891 \\
\hline Mirpur Khas & 1,651 & 23 & 4 & 46 & 274 & 1,998 \\
\hline Tharparkar & 3,024 & 42 & 7 & 21 & 345 & 3,439 \\
\hline Umerkot & 1,803 & 24 & 4 & 14 & 183 & 2,028 \\
\hline Sanghar & 2,465 & 18 & 2 & 41 & 429 & 2,955 \\
\hline Naushero Feroze & 1,802 & 20 & 13 & 53 & 347 & 2,235 \\
\hline Shaheed Benazirabad & 2,066 & 28 & 10 & 26 & 231 & 2,361 \\
\hline Total & 35,948 & 488 & 160 & 877 & 4,910 & 42,383 \\
\hline
\end{tabular}

The table 02 given below shown the dismal pictures of Sindh schooling infrastructure and indicated that vast majorities of schools at least $50 \%$ of the total schools in the province are without basic needs of human i.e. without electricity toilets and shelters from creeping.

The one eighth portions of total schools are shelter-less means students are learning under the trees and wooden huts made by the mud and wood pieces or do not have more than two rooms, excluding the percentage of non-functional schools which are closed by the vested interests' lobbies of the feudal mindset of 18th century with their political ill wills and others socio economic taboos in their territory. Among total of 42383 schools 23235 are without electricity,15478 are existing without washroom, 18128 without drinking water and 16359 are without boundary wall. The district wise details are showed in table 02 below for ready reference. 
Table02.

\begin{tabular}{|c|c|c|c|c|c|}
\hline \multirow[b]{2}{*}{ District } & \multirow[b]{2}{*}{ Schools } & \multicolumn{4}{|c|}{ Schools having Basic Facilities } \\
\hline & & Electricity & Washroom & Drinking Water & Boundary Wall \\
\hline Badin & 2,934 & 875 & 1,595 & 1,298 & 1,447 \\
\hline Dadu & 1,821 & 931 & 1,173 & 1,001 & 1,223 \\
\hline Hyderabad & 868 & 634 & 737 & 604 & 747 \\
\hline Jamshoro & 694 & 447 & 526 & 437 & 580 \\
\hline Mitiari & 829 & 633 & 622 & 635 & 635 \\
\hline Sujawal & 1,390 & 145 & 467 & 259 & 414 \\
\hline Tando Allah Yar & 760 & 492 & 561 & 432 & 615 \\
\hline Tando Muhammad Khan & 1,012 & 273 & 600 & 532 & 626 \\
\hline Thatta & 1,282 & 220 & 786 & 272 & 584 \\
\hline Central Karachi & 607 & 447 & 484 & 507 & 529 \\
\hline East Karachi & 264 & 223 & 241 & 219 & 238 \\
\hline Korangi Karachi & 550 & 397 & 431 & 391 & 509 \\
\hline Malir Karachi & 591 & 240 & 398 & 302 & 479 \\
\hline South Karachi & 482 & 383 & 426 & 356 & 432 \\
\hline West Karachi & 363 & 232 & 301 & 256 & 340 \\
\hline Jacobabad & 1,427 & 692 & 697 & 752 & 686 \\
\hline Kambar-Shahdadkot & 1,498 & 925 & 1,068 & 865 & 1,018 \\
\hline Kashmore & 1,368 & 391 & 610 & 804 & 581 \\
\hline Larkana & 1,158 & 799 & 915 & 954 & 1,001 \\
\hline Shikarpur & 1,101 & 465 & 675 & 774 & 816 \\
\hline Ghotki & 1,891 & 905 & 1,186 & 1,307 & 1,109 \\
\hline Khairpur Mirs & 3,290 & 2,142 & 2,357 & 2,765 & 2,067 \\
\hline SUKKUR & 1,187 & 738 & 866 & 870 & 837 \\
\hline Mirpur Khas & 1,998 & 793 & 1,293 & 936 & 971 \\
\hline Tharparkar & 3,439 & 550 & 1,814 & 715 & 1,559 \\
\hline Umerkot & 2,028 & 435 & 1,336 & 688 & 1,165 \\
\hline Naushero Feroze & 2,235 & 1,535 & 1,514 & 1,972 & 1,428 \\
\hline Sanghar & 2,955 & 830 & 1,776 & 1,665 & 1,724 \\
\hline Shaheed Benazirabad & 2,361 & 1,376 & 1,450 & 1,687 & 1,664 \\
\hline Grand Total & 42,383 & 19,148 & 26,905 & 24,255 & 26,024 \\
\hline Without Facilities & Vo Info & 23,235 & 15,478 & 18,128 & 16,359 \\
\hline
\end{tabular}

The valid secondary data of Sindh Education Management Information system further showed in details that a proximally 5000 (Five thousand schools) are still operating under the trees which we called as shelter less schools as reflected in data given in figure 01 below. The below mentioned data describe seriousness of the situation which is strongly correlated with literacy rate and quality education in governments schools. It needs to improve the situation of yellow school to increase rate of literacy at least 10 and we can easily increase girl's enrollment as double from 19 to more than 30\% in short run. The duplicated and deterred quality is also linked with worst situation of infrastructure in the Sindh province as reflected in figure 01 in details, which indicates that from total of 42383, only satisfactory conditioned schools are 13891urget needs of repair are 15978.The issue of shelter less schools and dangerous building are tragic scene of Sindh government schools which pose threat of life to the little kids and requires war foot strategy for improvements of the structure. Sindh is richest province of Pakistan but bad governance and biased development polices created southern and northern divide in the country which harms increasing rate of literacy means quantity and also quality education in the region at large and in result 4910 schools are without building and 6567 building are very dangers due to their poor-quality construction and near to collops. As per media reports every year several students are died and many others were injured due to roof collops of these buildings and insecure students are always remained under fear, they might be suffering from psychological problems due to insecure and fearful environments of dangerous and shelterless public schools in the province of Sindh-Pakistan. 
Figure 01

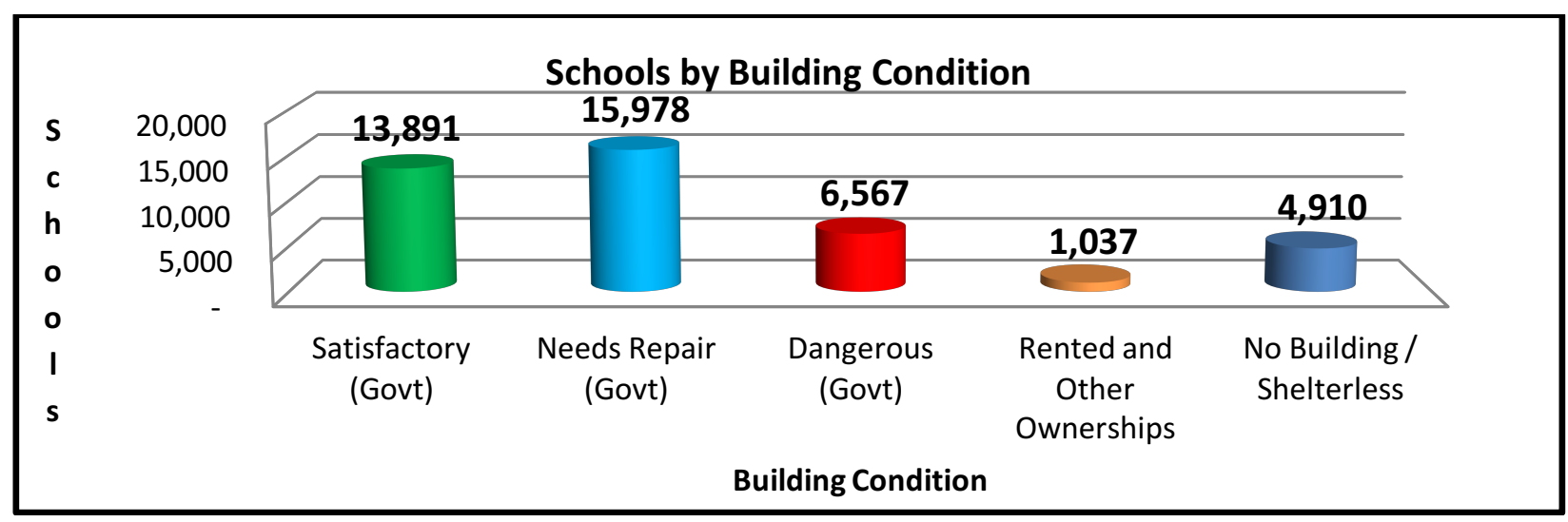

[4] Sindh Education Management Information System (SEMIS) Yearly Reports 16-17.

When we highlighting the fact of Sindh Southern province of Pakistan having pullulation of more than 500 million and half of it are illiterate in digital age of 21th century we find the poor infrastructure is the major obstacles in increasing quantity and also improving of quality at large.

Its alarming that approximately 50\% schools have no drinking water and above $40 \%$ have not toilet facilities and more than $60 \%$ are exciting without electricity in the digital age. Without updating and improving schooling infrastructural facilities we will be unable achieve the given or assigned milestone in given period of time 2030, as objected in global goals of united nations in 2016.

\section{Challenge of School Infrastructure Facilities and Sunk Cost of Public Expenditure}

The best infrastructure attracts more the student and their parents to enroll in public sector schools for wellbeing in education particularly girls' toilets faculties can increase at least 10\% enrollment per year. The poor facilities of drinking water electricity, furniture, lack of skilled teachers in schools, child's labour and chronic poverty in the country others are the major reasons of declining enrollment, equity and quality of education in Sindh.

The World Bank (2002) SAAVEDRA report on education financing stresses that education expenditure must be adequate, sustainable, and efficient. It concludes and suggests that "There is no theoretically optimum level of expenditure a country should devote to education. Under conditions of low system efficiency or high inequities or poor system organization, increasing spending may well prove to be the wrong medicine for the country's educational ailments. [6]

Nadia Naveen 2016 Woodrow Wilson policy institute scholar discussed this issue in details and describe that "The center of international and domestic attention, therefore, should be how countries are spending their own resources rather than how much they are spending. Most parents in Pakistan have an intimate understanding of how public sector resources are misused and why social services fail. Elites and internationals, whose children do not go to Pakistani government schools, have distanced themselves from the politics that govern the education sector by relying on metrics that are oversimplified but unintelligible to the common man, namely the percent of its GDP that Pakistan dedicates to education. [7]. It also indicated that the large-scale financial mismanagement in the public funds at large by the political and managerial elites of the country for their luxurious life on public cost damaged the basic facilities structure of the education department because after expenditure of 462 Billion only $2 \%$ literacy rate is increased in the province which alarming and needs to investigations of public spending's in details in greater public interest. The 05 years expenditure data has been 
analysis and focused on educational sector of Sindh which indicated that at least four hundred billion rupees are utilized for management and development of infrastructure of the sector mentioned table 03, but the real picture of the educational infrastructure in schools indicates poor state of facilities which is main reason of lower enrolment in public sector schools particularly female students affected at large because of unavailability of toilets, water supply and boundary wall for security.

Figure 02: Five Years Expenditure on Education Sector in Sindh Province

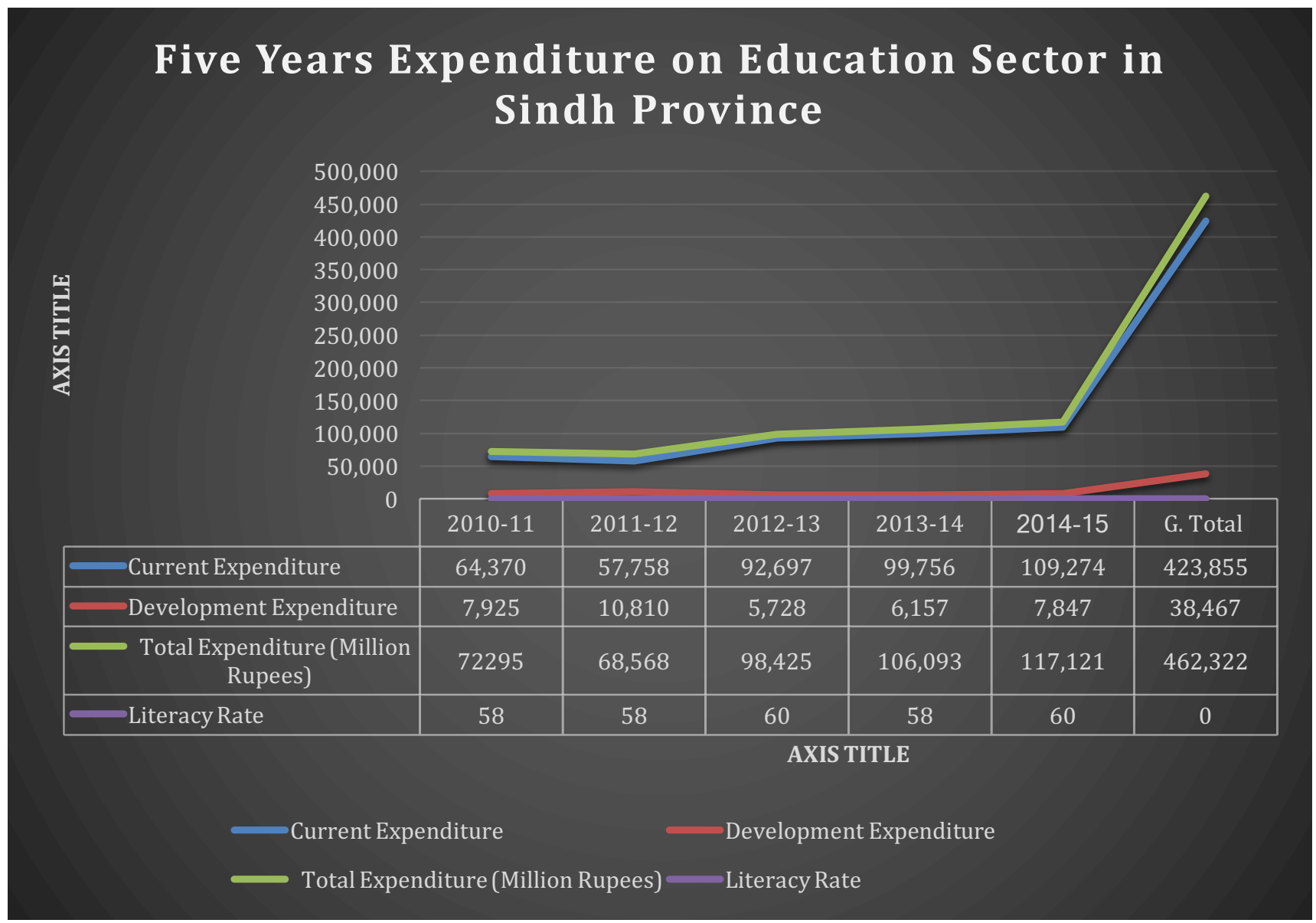

[5] Source: Pakistan Economic Survey-2016-17, Page 175

\section{CONCLUSION \& POLICY RECOMMENDATIONS}

It is experiments based evidence observed globally that school facilities affect widely on health, behavior, engagement, learning, and growth in achievement of both teachers and students at large. The infrastructures facilities are very essential for appropriate learning environments for students to improve the quality of education and to also increase student enrollment widely particularly in far flung area which is populated by the marginalized class of the society. Best structured and well-equipped environment friendly classrooms are played significant role to work with great enthusiasm and communicate effectively which is very helpful for real learning environment to support narratives of quality education. The major cause of out of school children are also correlated with infrastructural facilities in the school and congested space in the class rooms.

When analyses the data on the subject the most out of schools children are found in rural and hard area of Sindh and Pakistan i,e Thar/ cholistan/dusht/ desert area and hilly range of northern /western regions which cover the several hundred square kilometers respectively. 
These less privileged arid areas with very low literacy rates are because of school's poor infrastructure, basic facilities and other communications flaws. The shelterless and dangers building and without boundary walls schools are major obstacle in quality enhancement and gender-gap in the rural schools. The low literacy trends and gender gap in education is critical development challenge of Sindh - Pakistan.

In the greater public interest towards tomorrow people the communities may allow to establish their own infrastructures as per their geographical environments and to open their schools on subsidy-based to promote literacy in the region. Policymakers, educators, and others relevant stakeholder should focus on the need to ensure that students learn $21^{\text {st }}$ century skills through universal level minimums infrastructural facilities criteria to teach the students to make fine human resources needed to act globally. Policy make often overlook the infrastructure impact facilities can play in improving outcomes for both teachers and students with modern curriculum and infrastructural improvements. While improving facilities comes at a financial cost, the benefits of such investments often surpass the initial fiscal costs. Policymakers, thus, should focus greater attention on the impacts of facilities and adopt a long-term cost-benefit perspective on efforts to improve school facilities in greater public interest and as objected by united nations in sustainable goal o4 quality education for all.

It is research based evident observed widely that the poor classrooms structure and smaller learning centers reduces visual approach and others learning opportunities and its inversely related to student psychical and phycological development and achievement. There is need of new approaches and strategy to big push on infrastructure development in public sector schools and this means in broader perspectives that all resources may bring in one poll for investment in shortest possible period for improvement on urgent basis. The missing facilities of girl's schools should be first priority in this way at least more than $10 \%$ increase in enrollment can be achieved which will be helpful in long run to reduce the gender gap in literacy and women empowerment in the region.

When we plan to improve the school infrastructure in the Sindh province of Pakistan, we should focus 4910 schools running without building and 6567 buildings are very dangerous on humanitarian ground and among all these, first priority we should give is to girl's schools to reduce gender gap in the region and to bring out of school children in the institutions to increase the literacy and to enhance quality of education in the areas. It is also suggested to create international donors group investment pool and to develop joint strategy to tackle the infrastructural problems in a one goes to resolve the issue in sustainable way.

The public private partnerships can play an important role to provide infrastructure facilities and it will be more feasible to over the problem of soft and hard means structural infrastructure on long term and sustainable basis and also to develop the capacity of teachers and educational sector manager for global standard improvement's at large in Sindh Government Schools.

It's also concluded that mostly funds were remain un utilized every year due to different reasons the important are red tapes, technical anomalies, weak feasibility repots, ill wills of officials and lengthy/time bound procedure of planning and development board toward technical appraisal and financial releases from finance department but very important is the organizational mismanagement within the organization because of unavailability/lack of proper and robust procurement organization which is necessary to be established within the department due to its huge size and large scale of assignment which is necessary to be 
established within the department to plan the yearly procurement cycle with utmost care and trained the official concerned for effective proceedings and speedy progress of funds utilizations and best quality of construction as in the developed world to deliver in greater public interest.

\section{References:}

Pakistan Government of (2016), Economic Survey of Pakistan. Islamabad, Ministry of Finance \&Economic Affairs Division. pp.2, 13, 20, 21, 23.

Nooreen Mujahid \& Muhammad Noman (2015) Infrastructure Availability in the Public Sector Schools: A Case Study of Sindh Province. Journal of Education and Practice www.iiste.org ISSN 2222-1735 (paper) ISSN 2222-288X (Online) Vol.6, No.4, 2015.

The Alif Ailaan Education Report 2017, Islamabad Pakistan.

Sindh Education Management Information System (SEMIS) Yearly Reports 2015-16\&17.

Sanji Talreja (2017) Public Private Partnership (PPP) Guide \& Toolkit Public Private Partnership Node School Education \& Literacy Department Government of Sindh Karachi (Unpublished).

The World Bank (2002) SAAVEDRA report

Nadia Naveen 2016 "Pakistan's Education Crisis: The Real Story" Woodrow Wilson International Center for Scholars One Woodrow Wilson Plaza 1300 Pennsylvania Avenue NW Washington, D.C. 20004-

3027.www.wilsoncenter.org. pp 